\title{
Saturated Phytosterol
}

National Cancer Institute

\section{Source}

National Cancer Institute. Saturated Phytosterol. NCI Thesaurus. Code C68422.

Any fully saturated phytosterol, indicating that the 5- 6 bond of the sterol B ring has been oxidized. Saturated Phytosterols are in general produced by enzymatic hydrogenation of phytosterols. They are found in trace amounts in nuts, seed and legumes. Saturated phytosterols are not produced in the animal kingdom. 